\title{
Comparative and molecular analysis of MRSA isolates from infection sites and carrier colonization sites
}

\author{
Khaled R. Alkharsah ${ }^{1,2^{*}}$, Suriya Rehman ${ }^{1}$, Fatimah Alkhamis ${ }^{1}$, Amani Alnimr ${ }^{2}$, Asim Diab² and Amein K. Al-Ali
}

\begin{abstract}
Background: Methicillin resistant Staphylococcus aureus (MRSA) constitutes a major global health concern causing hospital and community acquired infections. A wide diversity of MRSA genotypes are circulating in geographically related regions. Therefore understanding the molecular epidemiology of MRSA is fundamental to design control and clearance measures.
\end{abstract}

Methods: A total of 106 MRSA isolates from infection (51) and carrier colonization sites (55) are characterized genetically based on SCCmec and MLST genotyping methods in addition to detection of PVL, TSST-1 and enterotoxins.

Results: Sccmec-IV was the most frequently detected genotype (77.3\%) followed by genotype V (13.2\%) and III (9.4\%). SCCmec-IVa was more prevalent among the carrier group ( $p$ value 0.002). CC80 was the most commonly identified clonal complex (CC). CC6 and CC22 were significantly more prevalent among the carrier group ( $p$ value 0.02 and 0.01 , respectively). PVL was highly prevalent among the isolates (58.5\%). PVL was detected in $70.6 \%$ of isolates from infection sites and $47.3 \%$ of isolates from carriers. All strains were sensitive to vancomycin, however, MRSA strains isolated from infection sites had significantly higher MICs compared to strains isolated from carrier colonization sites ( $p$ value 0.021). Five new sequence types mainly from the carrier group were identified and described in the study.

Conclusions: MRSA population is genetically very diverse among carriers and infected individuals. With SCCmec type IV being most prevalent, this suggests a community origin of most MRSA strains. Therefore very well designed surveillance and clearance strategies should be prepared to prevent emergence and control spread of MRSA in the community.

Keywords: MRSA, SCCmec, MLST, Carrier, Infection, Saudi Arabia, CA-MRSA, HA-MRSA

\section{Background}

Methicillin-resistant Staphylococcus aureus (MRSA) causes a wide variety of infections including life threatening infections. Consequently, MRSA is a global concern and it is one of the biggest threats in a health care facility [1]. The emergence of $S$. aureus strains resistant to methicillin and other categories of $\beta$-lactam antimicrobials was reported as early as 1960 s and was later attributed to the expression of a protein that binds penicillin with low affinity (PBP2a) [2]. PBP2a is encoded by $m e c A$ gene

\footnotetext{
*Correspondence: kalkharsah@iau.edu.sa

2 Department of Microbiology, College of Medicine, Imam Abdulrahman Bin Faisal University (IAU), P.O. Box 1982, Dammam 31441, Saudi Arabia Full list of author information is available at the end of the article
}

(a small 2007 bp), a mobile extrinsic genetic element that is carried on a genomic island called staphylococcal cassette chromosome mec (SCCmec) [3]. According to the International Working Group on the Classification of Staphylococcal Cassette Chromosome Elements (IWGSCC), eleven genotypes of MRSA have been identified based on the type of SCCmec [4]. SCCmec types I-III are generally detected in hospital acquired MRSA (HAMRSA), which are the strains reported to cause hospital associated infections and outbreaks [5]. Other SCCmec types (IV, V or VII) are more frequently detected in community acquired MRSA (CA-MRSA), which cause infections in otherwise healthy individuals who had not been previously hospitalized [5]. However, CA-MRSA strains 
are increasingly reported in hospitals causing healthcare associated infections [6]. Data from clinical and epidemiologic studies provide convincing indication that attribute the increased virulence of CA-MRSA over the HA-MRSA to the lukF-PV and lukS-PV (PVL) genes, which make the Panton-Valentine leukocidin (PVL) [7]. PVL causes cell lysis and is considered as a genetic symbol for CA-MRSA strains [8], however, PVL positive HAMRSA has been reported in different studies [7].

MRSA strains could be also grouped into biologically meaningful groups called clonal complexes $(\mathrm{CC})$ based on sequencing fragments from seven housekeeping genes in a method called multi locus sequence typing (MLST) [9]. CC showed geographically distinct distribution. For example, sequence types (ST) such as ST5 and ST8, belonging to $\mathrm{CC} 5$ and $\mathrm{CC} 8$ respectively, are commonly found in the United States and Japan, whereas strains belonging to the clonal complexes $\mathrm{CC} 22$ are more commonly found in Europe and Australia [10]. The ST80 (CC80) strain has been detected widely in the Middle East [11].

Hospitalization appears to present a patient with a major risk of infection with $S$. aureus. However, studies have shown that about one-fifth to one-third of the population carry S. aureus in their nose and about 2-3\% of people carry MRSA [12]. In health care workers, this percentage increases to approximately $5 \%$ [13]. S. aureus carriers are another major risk factor and source of infection. The transmission of MRSA in hospitals and community needs to be better understood to determine the prevalence and peculiarity of circulating MRSA. Studies conducted in European hospitals on MRSA carriers have shown large variations in genetic diversity and in the prevalence of MRSA strains [14, 15]. Screening and identification of hospitalized MRSA carriers will result in a more effective control of MRSA.

In the current study, we have characterized MRSA strains isolated from carriers or infected individuals from the Eastern Province of Saudi Arabia and compared their genotypes and antibiotic susceptibility patterns. A better understanding of the circulating MRSA strains will result in a greater control and management of the disease.

\section{Methods}

\section{Study design and bacterial isolates}

A cross-sectional study was conducted from January 2010 to September 2011 at King Fahd hospital of the University (KFHU) in Al-Khobar in the Eastern Province of Saudi Arabia. A total of 106 MRSA isolates were collected from the microbiology laboratory of the hospital during the period of the study. All of these isolates were identified using standard microbiology procedures were confirmed using Vitek II (biomerieux, France).
The isolates were confirmed for their resistance to oxacillin and cefoxitin using the disc diffusion method as described below. Clinical and demographic data were collected from patients' medical records.

Ethical approval for the study was obtained from the Institutional Review Board at the University of Dammam (IRB-2013-08-023).

\section{Antimicrobial susceptibility testing}

Twenty-four antibiotics were used in disc diffusion method on Mueller-Hinton agar (Oxoid, Hampshire, England) according to the Clinical Laboratory Standard Institute [16]. All antibiotic discs were purchased from Oxoid (Oxoid, Hampshire, England). Vancomycin susceptibility testing was performed by the $\mathrm{E}$ test strips $(\mathrm{AB}$ Biodisk, Sweden) [16].

\section{Molecular genotyping \\ Extraction of DNA}

Bacterial DNA was extracted using Qiagen DNA extraction kit (Qiagen, Hilden, Germany) according to the manufacturer's instructions. Extracted DNA was stored at $-80{ }^{\circ} \mathrm{C}$ till the time of analysis.

\section{Detection of mecA and pvl genes}

A multiplex PCR previously developed by Al-Talib et al. [17] was used to identify methicillin-resistant Staphylococcus by detecting the mecA gene. Additionally this multiplex PCR detects the presence of lukS gene of the Panton-Valentine leukocidin. To identify the genus Staphylococcus and to discriminate S. aureus from coagulase negative staphylococci, the primer-cocktail comprised primers targeting the 16S rRNA gene and the femA gene, respectively [17]. The internal control primers, originally included in Al-Talib protocol, were not included in our master mix. A laboratory isolate previously known to be positive for mecA and $P V L$ genes was used as positive control. A water negative control was used with each run.

\section{Detection of other staphylococcal virulence toxins}

Two sets of primers were used in two multiplex PCR reactions (A and $\mathrm{B})$ for detection of the staphylococcal enterotoxins genes $A$ to $E$, toxic shock syndrome toxin 1 (tsst-1), and exfoliative toxins $A$ and $B$ according to Mehrotra et al. [18].

\section{SCCmec typing}

We followed a multiplex PCR protocol developed by Ghaznavi-Rad et al. for SCCmec genotyping [19]. The method uses nine pairs of primers to detect the SCCmec genotypes (I-III, IVa-IVd, IVh, and V) in addition to primers for $S$. aureus identification and detection of 
methicillin resistance $m e c A$ gene [19]. The PCR program was followed as described by Ghaznavi-Rad et al. [19]. The PCR product was run on $1.8 \%$ metaphor agarose (Lonza, Rockland, USA) at $25 \mathrm{~V}$ overnight in $0.5 \times \mathrm{TBE}$ buffer for good separation and size-based discrimination of the DNA bands.

\section{MLST genotyping and sequence analysis}

The multi locus sequence typing (MLST) protocol for $S$. aureus was followed according to the instructions on the MLST.net website (http://saureus.beta.mlst.net/). The allelic profile of each isolate was obtained and compared to the database to obtain the sequence type (ST). eBurst algorithm (http://saureus.beta.mlst.net/\#eBURST) was used to categorize MLST into groups and clonal complexes (CC).

\section{Data analysis}

Statistical analysis was performed using SPSS version 23 and OpenEpi software. Phylogenetic tree of the STs was performed by eBurst.

\section{Results}

The 106 MRSA isolates included in this study were obtained from 39 females (36.8\%) and 67 males (63.2\%) with an average age of 27.1 years (Table 1). Fifty-one strains (48.1\%) were isolated from infection sites, including wound (16\%), abscess (14.2\%), skin and tissue infections (5.7\%), and lower respiratory tract infections (4.7\%). MRSA strains isolated from ear, eye and throat infections were less frequent $(1.9 \%$ each). One strain was isolated from cerebrospinal fluid $(0.94 \%)$ and one from a patient with a urinary tract infection (0.94\%). Fifty-five strains (51.9\%) were isolated from colonization sites such as nose (40.6\%), throat (6.6\%), axilla (2.8\%) and groin (1.9\%). MRSA strains isolated from colonization sites were isolated from Patients hospitalized for diseases not related to MRSA infection. The detection of MRSA in these patients was performed as a part of infection control policy which placed patients suspected or confirmed to be MRSA positive under contact isolation until decolonization is proven after successful prophylactic nasal mupirocin ointment and chlorhexidine body wash therapy. There was no statistically significant correlation between MRSA isolation from infection or colonization sites on the basis of age, duration of hospitalization, ICU admission, or outcome of treatment (Table 1).

All MRSA isolates were positive for mecA, femA, and sa442 genes. The most frequently detected $\mathrm{SCCmec}$ genotype was SCCmec-IV (77.3\%) followed by SCCmec-V (13.2\%), and III (9.4\%). Further subtyping of SCCmecIV revealed that subtypes IVa and IVc are the only subtypes prevalent among the isolates (41.5 and 58.5\%, respectively) (Table 2). SCCmec-IVa genotype was more frequently found in MRSA isolated from the carriers compared to infected individuals ( $\mathrm{p}$ value 0.002 , OR 3.84) (Table 2).

MLST genotyping of the MRSA isolates showed that ST80 is the most frequently encountered genotype in our study (34.9\%) followed by ST22 (10.4\%) (Table 2 and

Table 1 Frequency of MRSA isolates from carrier colonization sites and infection sites with demographic and clinical data

\begin{tabular}{|c|c|c|c|c|}
\hline & Carrier $(n=55)$ & Infection $(n=51)$ & $p$ value & OR $(95 \% \mathrm{Cl})$ \\
\hline \multicolumn{5}{|l|}{ Gender } \\
\hline Male & 32 & 35 & 0.27 & $0.64(0.28-1.42)$ \\
\hline Female & 23 & 16 & & \\
\hline \multicolumn{5}{|l|}{ Age $\left(\right.$ years) ${ }^{a}$} \\
\hline$\leq 30$ & 34 & 32 & 0.9 & $0.96(0.43-2.12)$ \\
\hline$>30$ & 20 & 18 & & \\
\hline \multicolumn{5}{|l|}{ ICU admission ${ }^{b}$} \\
\hline Yes & 51 & 48 & 0.67 & $0.53(0.02-7.21)$ \\
\hline No & 2 & 1 & & \\
\hline \multicolumn{5}{|l|}{ Duration of hospitalization (days) } \\
\hline$\leq 7$ & 24 & 20 & 0.65 & $1.12(0.55-2.63)$ \\
\hline$>7$ & 31 & 31 & & \\
\hline \multicolumn{5}{|l|}{ Treatment outcome ${ }^{c}$} \\
\hline Discharged rescreened negative & 26 & 27 & 0.36 & $0.58(0.17-1.84)$ \\
\hline Discharged rescreened positive & 10 & 6 & & \\
\hline
\end{tabular}

\footnotetext{
a One sample from each group has no data

b Two samples from each group have no data

c 37 patients discharged without further screen
} 
Table 2 Molecular characterization of MRSA isolates from infection sites and carrier colonization sites

\begin{tabular}{|c|c|c|c|c|c|}
\hline & Genotype & Carrier (55) & Infection (51) & p value & OR $(95 \% \mathrm{CI})$ \\
\hline \multirow[t]{4}{*}{ sccmec } & III & 3 & 7 & 0.17 & $0.37(0.07-1.48)$ \\
\hline & IVa & 25 & 9 & 0.002 & $3.84(1.59-9.81)$ \\
\hline & IVc & 21 & 27 & 0.13 & $0.55(0.25-1.20)$ \\
\hline & V & 6 & 8 & 0.49 & $0.66(0.20-2.1)$ \\
\hline \multirow[t]{10}{*}{$M L S T^{a}$} & CC1 (ST1, ST772) & 5 & 8 & 0.30 & $0.53(0.15-1.76)$ \\
\hline & CC5 (ST5, ST149) & 4 & 5 & 0.64 & $0.71(0.16-2.96)$ \\
\hline & CC6 (ST6) & 6 & 0 & 0.02 & Undefined \\
\hline & CC8 (ST8,ST239, ST241) & 3 & 8 & 0.091 & $0.31(0.06-1.19)$ \\
\hline & CC22 (ST22) & 10 & 1 & 0.01 & $10.7(1.70-242)$ \\
\hline & CC30 (ST30) & 0 & 2 & 0.23 & Undefined \\
\hline & CC45 (ST46) & 2 & 0 & 0.27 & Undefined \\
\hline & CC80 $(\mathrm{ST} 80, \mathrm{ST} 1440)^{\mathrm{b}}$ & 21 & 23 & 0.43 & $0.73(0.33-1.59)$ \\
\hline & CC88 (ST88) & 3 & 2 & 0.76 & $1.38(0.20-12)$ \\
\hline & CC97 (ST97) & 1 & 1 & 0.95 & $0.91(0.02-36.08)$ \\
\hline \multirow[t]{2}{*}{$P V L$} & Pos & 26 & 36 & 0.02 & $0.38(0.17-0.84)$ \\
\hline & Neg & 29 & 15 & & \\
\hline \multirow[t]{2}{*}{ sea } & Pos & 16 & 22 & 0.14 & $0.54(0.24-1.22)$ \\
\hline & Neg & 39 & 29 & & \\
\hline \multirow[t]{2}{*}{ seb } & Pos & 7 & 1 & 0.04 & $7.18(1.06-168.6)$ \\
\hline & Neg & 48 & 50 & & \\
\hline \multirow[t]{2}{*}{$\sec$} & Pos & 0 & 0 & NA & NA \\
\hline & Neg & 55 & 51 & & \\
\hline \multirow[t]{2}{*}{ sed } & Pos & 3 & 0 & NA & NA \\
\hline & Neg & 52 & 51 & & \\
\hline \multirow[t]{2}{*}{ see } & Pos & 11 & 6 & 0.26 & $1.86(0.63-5.88)$ \\
\hline & Neg & 44 & 45 & & \\
\hline \multirow[t]{2}{*}{ eta } & Pos & 0 & 0 & NA & NA \\
\hline & Neg & 55 & 51 & & \\
\hline \multirow[t]{2}{*}{ etb } & Pos & 0 & 0 & NA & NA \\
\hline & Neg & 55 & 53 & & \\
\hline \multirow[t]{2}{*}{ tst } & Pos & 8 & 7 & 0.91 & $1.07(0.35-3.34)$ \\
\hline & Neg & 47 & 44 & & \\
\hline Average vancomycin MIC & & 0.81 & 1.26 & $0.021^{\$}$ & $(0.35-0.55)$ \\
\hline
\end{tabular}

sea, seb, sec, sed, and see staphylococcal enterotoxin A, B, C, D, and E

eta and etb exfoliative toxin $\mathrm{A}$ and $\mathrm{B}$

tst toxic shock toxin

a One of the isolates in infection group was a singleton in eBurst and could not be allocated to any CC

b Includes also the 4 new STs from 6 samples according to eBurst

$\$ p$ value (two-tailed) from Hartley's $f$ test for equality of variance

Fig. 1). ST6 and ST22 were more frequently detected in the carrier group than the infection group ( $\mathrm{p}$ value $=0.02$ and 0.01, respectively) (Table 2). Other MLST genotypes, such as ST30, ST1930, ST239 and ST241 were more frequently detected among the infected patients but were statistically not significant (Table 2).

Toxic shock syndrome toxin 1 (TSST-1) was present in $14.2 \%$ of the isolates. Staphylococcal enterotoxin A (SEA) was the most frequently detected enterotoxin (35.8\%)
(Table 2). SEB was significantly more prevalent among the carrier group compared to the infection group ( $\mathrm{p}$ value 0.04) (Table 2).

Panton-Valentine leucocidin (PVL) was positive in $58.5 \%(62 / 106)$ of the total MRSA isolates. It was more frequently detected in the infection group of MRSA isolates $(70.6 \%)$ compared to the carrier group isolates (47.3\%) (p value 0.02 , Table 2 ). However, when analyzing the prevalence of PVL among the MRSA isolates from 


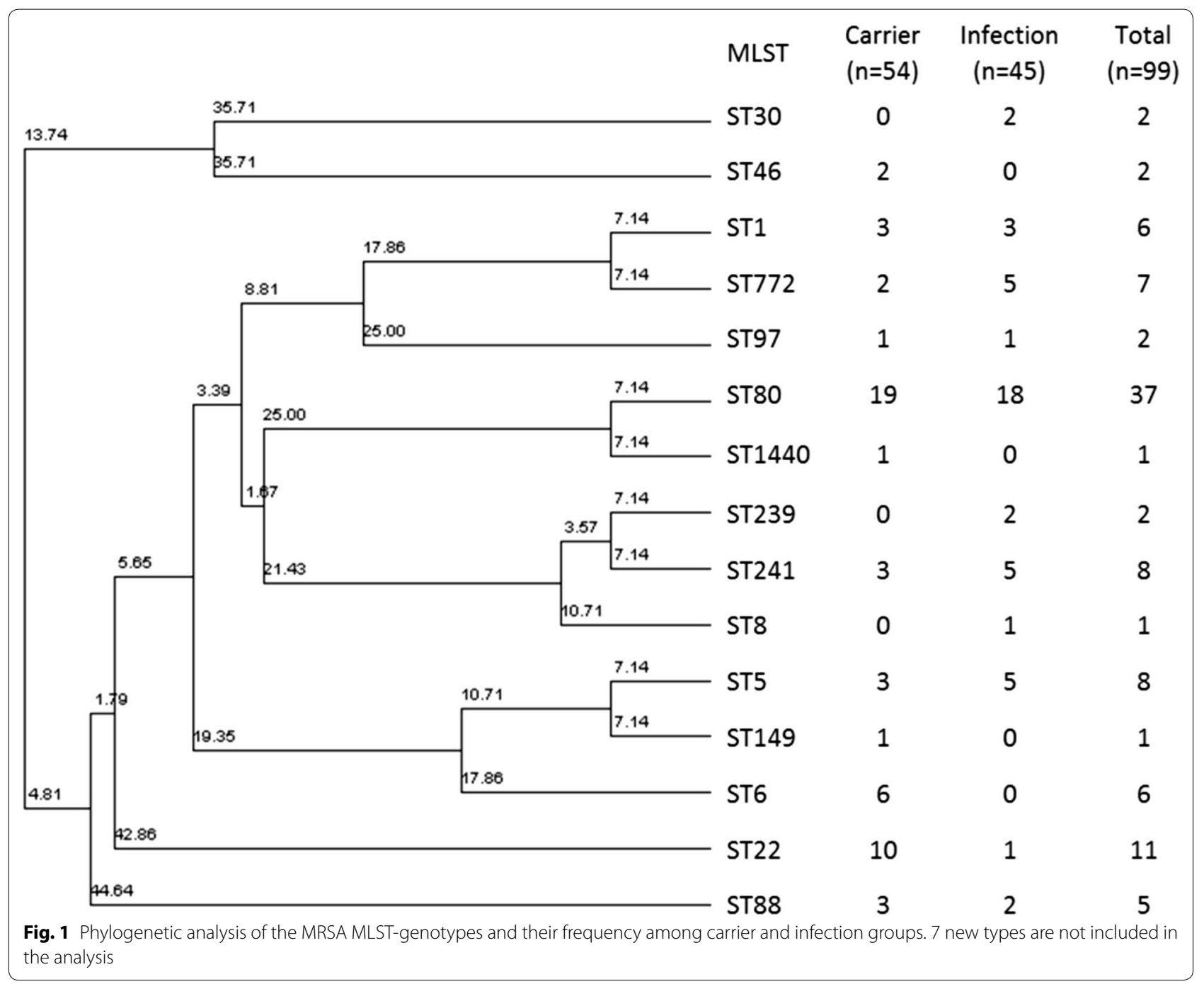

Table 3 Prevalence of PVL among the MRSA isolates from infection sites

\begin{tabular}{lllll}
\hline & $\begin{array}{l}\text { CA-MRSA } \\
(\mathbf{n}=\mathbf{3 2})\end{array}$ & $\begin{array}{l}\text { HA-MRSA } \\
(\mathbf{n}=\mathbf{1 9})\end{array}$ & p value & OR (95\% Cl) \\
\hline PVL & & & & \\
Pos & 24 & 12 & 0.4 & $1.7(0.49-6.1)$ \\
Neg & 8 & 7 & &
\end{tabular}

${ }^{a}$ According to our hospital infection control policy, the CDC classification of MRSA was used to classify MRSA as CA or HA

infection sites only based on whether these isolates are CA or HA-MRSA, PVL was more frequently detected in the CA-MRSA isolates but this difference was not statistically significant (Table 3 ).

Clonal complex 80 (CC80) was the most frequent clonal complex detected in the study (41.51\%) (Table 4 ) followed by CC1 (12.26\%), CC 8 and CC22 (10.38\% each), CC5 (8.49\%), CC6 (5.66\%), CC88 (4.71\%). CC30, CC45, and $\mathrm{CC} 97$ were the least frequent isolates in the study (1.89\% each) (Table 4). One new isolate was not possible to classify into any of the clonal complexes $(0.94 \%)$ and seem to constitute singleton. Most of the clonal complexes harbored SCCmec type IV (IVa or IVc). SCCmec in ST239 and ST241 (CC8) was of type III only (Table 4).

All MRSA isolates were sensitive to vancomycin, however, MRSA strains isolated from infection sites had significantly higher minimum inhibitory concentrations (MIC) compared to strains isolated from carrier colonization sites ( $\mathrm{p}$ value 0.021 ) (Table 2). There was no other significant difference in the antibiotic susceptibility pattern between MRSA isolates from infection sites and carrier colonization sites (Table 5). PVL was not associated with any antibiotic susceptibility pattern. 
Table 4 Affiliation of MRSA isolates MLST, SCCmec, PVL, and TST to clonal complexes

\begin{tabular}{|c|c|c|c|c|c|c|c|}
\hline $\mathrm{CC}$ & MLST & SCCmec & PVL & TST & Carrier & Infection & Total \\
\hline \multirow[t]{4}{*}{ CC1 } & ST1 & IVa & Neg & Neg & 3 & 2 & 5 \\
\hline & & IVC & Pos & Neg & 0 & 1 & 1 \\
\hline & ST772 & IVa & Pos & Neg & 0 & 1 & 1 \\
\hline & & V & Pos & Neg & 2 & 4 & 6 \\
\hline \multirow[t]{5}{*}{ CC5 } & ST5 & IVC & Neg & Pos & 0 & 2 & 2 \\
\hline & & & Pos & Neg & 1 & 1 & 2 \\
\hline & & V & Neg & $\mathrm{Neg}$ & 2 & 0 & 2 \\
\hline & & & Pos & Neg & 0 & 2 & 2 \\
\hline & ST149 & IVa & Neg & Neg & 1 & 0 & 1 \\
\hline CC6 & ST6 & $\mathrm{IVa}$ & Neg & Neg & 6 & 0 & 6 \\
\hline \multirow[t]{3}{*}{ CC8 } & ST8 & IVa & Pos & Neg & 0 & 1 & 1 \\
\hline & ST239 & III & Neg & Neg & 0 & 2 & 2 \\
\hline & ST241 & III & Neg & Neg & 3 & 5 & 8 \\
\hline \multirow[t]{3}{*}{ CC22 } & ST22 & $\mathrm{IVa}$ & Neg & Pos & 7 & 1 & 8 \\
\hline & & & Pos & Neg & 1 & 0 & 1 \\
\hline & & IVC & Pos & $\mathrm{Neg}$ & 2 & 0 & 2 \\
\hline \multirow[t]{2}{*}{ CC30 } & ST30 & IVa & Pos & Pos & 0 & 1 & 1 \\
\hline & & IVC & Pos & Neg & 0 & 1 & 1 \\
\hline CC45 & ST46 & IVC & Neg & Neg & 2 & 0 & 2 \\
\hline \multirow[t]{7}{*}{ CC80 } & ST80 & IVa & Neg & Neg & 3 & 0 & 3 \\
\hline & & & Pos & Neg & 1 & 0 & 1 \\
\hline & & IVC & Neg & Neg & 1 & 0 & 1 \\
\hline & & & Pos & Pos & 0 & 2 & 2 \\
\hline & & & Pos & Neg & 13 & 15 & 28 \\
\hline & & V & Pos & Neg & 1 & 1 & 2 \\
\hline & ST1440 & IVc & Pos & Neg & 1 & 0 & 1 \\
\hline \multirow[t]{3}{*}{ CC88 } & ST88 & IVa & Neg & Neg & 0 & 1 & 1 \\
\hline & & & Pos & Pos & 1 & 0 & 1 \\
\hline & & & Pos & Neg & 2 & 1 & 3 \\
\hline CC97 & ST97 & V & Neg & Neg & 1 & 1 & 2 \\
\hline
\end{tabular}

Five new MLST alleles from seven samples were identified in this study (Table 6). The isolates were obtained from scalp abscess, endotracheal aspirate, breast abscess, skin swab (cellulitis), urine, wound swab and one sample from nasal swab (Table 6). These alleles produced new sequence types (STs) that have not been previously described in the MLST database. All except one were PVL positive and harbored the SCCmec-IV (Table 6).

\section{Discussion}

Extensive knowledge of the circulating MRSA strains is an important prerequisite for control and surveillance measures. Little is known about the genetic diversity of MRSA in the Middle East and the Gulf area. The Arabian Gulf countries attract a wide range of working manpower from different countries, which in turn enriches the microbial diversity in these countries. In the current study we characterized the MRSA isolates from the Eastern Province in Saudi Arabia and compared the molecular types of these isolates from infection sites and from carrier colonization sites.

We did not find difference between the two groups regarding duration of hospitalization. Other studies have reported that MRSA infection prolongs the duration of hospitalization [20]. However, the type of infections in our study comprises mainly skin infections (abscess and wound) which do not necessarily require hospitalization. Interestingly, we found some molecular types confined to either the carrier or infection sites.

The most frequently detected SCCmec was type IV (IVa and IVc), which is in line with a previous study from the same region [21]. Type IV SCCmec is typically detected in MRSA isolates from samples outside hospitals [4, 5]. In our study SCCmec type IV strains were equally detected in carriers and from infection sites (Table 2). SCCmec subtype IVa was significantly associated with strains 
Table 5 Frequency of antibiotic resistance among the isolated strains

\begin{tabular}{|c|c|c|c|c|}
\hline Antibiotic & Carrier $(n=55)$ & Infection $(n=51)$ & $p$ value & Odds ratio $(\mathrm{Cl} 95 \%)$ \\
\hline Amikacin & $7(12.7 \%)$ & $10(19.6 \%)$ & 0.35 & $0.60(0.20-1.74)$ \\
\hline Azithromycin & $26(47.3 \%)$ & $27(52.9 \%)$ & 0.57 & $0.80(0.37-1.72)$ \\
\hline Cefoxitin & 55 (100\%) & $51(100 \%)$ & NA & NA \\
\hline Chloramphenicol & $53(96.4 \%)$ & $49(96.1 \%)$ & 0.94 & $1.08(0.11-10.71)$ \\
\hline Ciprofloxacin & $27(49.1 \%)$ & $31(60.8 \%)$ & 0.24 & $0.62(0.29-1.36)$ \\
\hline Clindamycin & $3(5.5 \%)$ & $5(0.1 \%)$ & 0.43 & $0.53(0.10-2.44)$ \\
\hline Doxycycline & $21(38.2 \%)$ & $19(37.3 \%)$ & 0.92 & $1.04(0.47-2.3)$ \\
\hline Erythromycin & $43(78.2 \%)$ & $40(78.4 \%)$ & 0.98 & $0.99(0.38-2.52)$ \\
\hline Fosfomycin & $3(5.5 \%)$ & $1(0.02 \%)$ & 0.41 & $2.86(0.29-77.36)$ \\
\hline Fusidic acid & 55 (100\%) & $51(100 \%)$ & NA & NA \\
\hline Gentamycin & $5(9.1 \%)$ & $10(19.6 \%)$ & 0.13 & $0.41(0.12-1.30)$ \\
\hline Kanamycin & $38(69.1 \%)$ & $41(80.4 \%)$ & 0.19 & $0.55(0.22-1.34)$ \\
\hline Levofloxacin & $8(14.5 \%)$ & $10(19.6 \%)$ & 0.50 & $0.70(0.24-1.97)$ \\
\hline Linezolid & $0(0 \%)$ & $0(0 \%)$ & NA & NA \\
\hline Ofloxcacin & $7(12.7 \%)$ & $9(17.6 \%)$ & 0.50 & $0.68(0.22-2.03)$ \\
\hline Oxacillin & $55(100 \%)$ & $51(100 \%)$ & NA & NA \\
\hline Vancomycin & $0(0 \%)$ & $0(0 \%)$ & NA & NA \\
\hline Quinu_Dalfo & $9(16.4 \%)$ & $5(0.1 \%)$ & 0.34 & $1.79(0.56-6.31)$ \\
\hline Rifampicin & $2(3.6 \%)$ & $1(0.02 \%)$ & 0.66 & $1.88(0.14-56.7)$ \\
\hline Sulphamethoxazol & $3(5.5 \%)$ & $2(0.04 \%)$ & 0.74 & $1.41(0.20-12.27)$ \\
\hline Teicoplanin & $53(96.4 \%)$ & 50 (98\%) & 0.66 & $0.53(0.02-7.19)$ \\
\hline Tetracycline & $36(65.5 \%)$ & $36(70.6 \%)$ & 0.58 & $0.79(0.34-1.81)$ \\
\hline Tigecycline & 53 (96.4\%) & 46 (90.2\%) & 0.23 & $2.85(0.54-22.1)$ \\
\hline Tobramycin & $4(7.3 \%)$ & $7(13.7 \%)$ & 0.30 & $0.50(0.12-1.83)$ \\
\hline
\end{tabular}

Table 6 Characteristics of the new ST alleles found in the study

\begin{tabular}{|c|c|c|c|c|c|c|c|c|c|c|}
\hline \multicolumn{7}{|c|}{ MLST genes } & \multirow[t]{2}{*}{$\mathrm{CC}$} & \multirow[t]{2}{*}{ SSCmec } & \multirow[t]{2}{*}{ PVL } & \multirow[t]{2}{*}{ Type of sample } \\
\hline $\operatorname{arcC}$ & aroE & $g l p F$ & $g m k$ & pta & tpi & yqil & & & & \\
\hline 1 & 3 & 1 & 14 & 4 & 51 & 10 & 80 & IVc & Pos & Scalp abscess \\
\hline 1 & 3 & 1 & 14 & New & 51 & 10 & 80 & IVc & Pos & Endotracheal aspirate \\
\hline 1 & New & 1 & 14 & 11 & 51 & 10 & 80 & IVc & Pos & Nasal swab \\
\hline 1 & New & 1 & 14 & 11 & 51 & 10 & 80 & IVc & Pos & Breast abscess \\
\hline 1 & New & 1 & 14 & 11 & 51 & 10 & 80 & IVc & Pos & Skin swab (cellulitis) \\
\hline 3 & New & 1 & 1 & 4 & 4 & 3 & ND & IVa & Neg & Urine \\
\hline 1 & 3 & 1 & 14 & 11 & New & 10 & 80 & IVC & Pos & Wound swab \\
\hline
\end{tabular}

ND not determined, Pos positive, Neg negative

isolated from carrier colonization sites. Sccmec type V, which is commonly associated with CA-MRSA infections [5], was equally detected in isolates from carriers and infection sites in our study. Similarly the sequence types ST6 and ST22 (except for one case) were only detected in MRSA isolates from carriers in our study.

PVL was highly prevalent among our isolates (56.5\%), an observation which has been reported elsewhere [21, $22]$. However, other studies reported a lower prevalence
(8-12\%) [23, 24]. Moreover, PVL was significantly associated with MRSA strains isolated from infection sites compared to carriers. Among MRSA isolates from infection sites, PVL was more frequently found in CA-MRSA, which is consistent with the literature [25]. Nonetheless, our study found that a large number of HA-MRSA isolates from infection sites harbor PVL (63.1\%). This indicates that PVL-positive strains are invading hospitals and causing infections, which is in line with previous reports 
[26]. Despite the controversial role of PVL as virulence factor in MRSA pathogenesis [27, 28], it seems to play an important role in the successful evolutionary fitness of these strains [15]. Therefore, special control and clearance measure should be directed toward PVL-positive MRSA. Four MRSA strains were found to be simultaneously positive for both PVL and TSST- 1 genes in our study, which is otherwise uncommon [29]. One of the four isolates was obtained from a patient with severe necrotizing pneumonia that required ventilation and developed sepsis and one isolate was obtained from deep cutaneous abscess. The other two isolates came from surgical wound infection and colonization sites. A similar finding has also been reported in the Middle East and other countries [29-32].

The most commonly identified clonal complex in our study was the CC80-MRSA-IV. This has been previously reported in several countries in the Middle East and North Africa and has also been reported from Riyadh in the central region of Saudi Arabia [11, 21, 22, 33-37]. This could indicate that it is the most common MRSA strain circulating in Saudi Arabia. This clone represents the European CA-MRSA clone. The spread of this clone in the Middle East and North Africa and the presence of sporadic cases in Europe suggest that this clone was introduced to Europe through migration from both the Middle East and North Africa. CC80-MRSA-IV isolates are usually PVL positive. However, PVL negative clones have been sporadically reported [11, 21, 35, 38, 39]. Four of the CC80-MRSA-IV isolates in our study were PVL negative. Since it has been suggested that PVL provides fitness to this isolate, in addition to the presence of this isolate in small numbers, it could be assumed that they are sporadic deletion variants. ST1440-IV was detected in only one sample in the present study. This isolate is very rare and has only been reported in Tunisia [40]. ST80-MRSA-V was identified in two cases in our study. This genotype has not been reported previously and seems to be a new isolate as all reported ST80 strains harbor the SCCmec genotype IV.

Two sequence types (ST1 and ST772) belonging to CC1 were identified in our study. Most ST1 strains were PVL negative and harbored SCCmec-IV, which may resemble the West Australian strain WA MRSA-1. The rest were PVL-positive strain, which may resemble the USA400 strain. ST772-MRSA-V is usually more distinct from the other $\mathrm{CC} 1$ isolates and is known as the Bengal Bay clone. This strain is more prevalent in India [41] and was also detected in many European countries, where it was linked to transmission associated with migration to these countries [42]. Similarly, the detection of this strain in Saudi Arabia could be explained by the presence of the large number of Indian workers in the country. The detection of ST772-MRSA-IV has not been previously reported and it was isolated from one case in our study.

The UK-MRSA-15 strain, which is also called Barnim Epidemic strain (C22-MRSA-IV PVL-negative), was detected in $7.5 \%$ of our isolates and was found more frequently among carriers. Similar to other reports, it differs from the UK-MRSA-15 strain in that it is positive for the tst1 gene and has the SSC-IVa [22]. The other PVL-positive strain was detected in three cases and was confined to the carrier group. This strain has been reported in many other countries, including the neighboring United Arab Emirates [15].

Contrary to other studies from Riyadh in Saudi Arabia [21, 22], ST241-MRSA-III PVL-negative strain was the most frequently detected isolate belonging to $\mathrm{CC} 8$, which indicates interregional variation in the distribution of these strains. This isolate has been reported in Kuwait, Tunisia, Taiwan and Poland [43-46]. The other CC8 strains were the ST239-MRSA-III and the USA300 (ST8-MRSA-IV PVL-positive) were previously reported from Riyadh region [21, 22].

Similar to previous reports from Saudi Arabia, PVLnegative and positive CC5 strains harboring the SCCmec IV or V were identified in our study [21, 22]. These strains were isolated also in Qatar, Tunisia and Egypt [24, $44,47,48]$. One sample in our study has genotypes similar to the Maltese strain (CC 5/ST149) [49].

All the CC6 isolates were detected in the carrier group and they were also reported previously in Riyadh and the United Arab Emirate [15, 22], which indicates that it is an established strain in the region.

Other clonal complexes such as CC30, CC45 and CC97 were isolated from $1.9 \%$ of the cases each. ST30-MRSAIV PVL-positive resembles the US1100 (southwest pacific clone) and is widespread in Europe and the Gulf region [15, 50]. Interestingly, CC45-MSSA strains were previously detected in Saudi Arabia from nasal colonization carriers [51]. Therefore, it is possible that this strain has acquired the mecA gene and transformed to MRSA. CC45-MRSA-IV was also reported previously in one case from Riyadh in Saudi Arabia [21] and one case from Hong Kong. Similarly, the CC97-MRSA-V was sporadically reported from many countries, including the Middle Eastern region [15].

The phenomenon of vancomycin MIC creep was described by Wang et al. and confirmed by several reports worldwide [52]. In MRSA strains, high vancomycin MICs, which still lay within the susceptible range $(\geq 1.0$ ), was linked with poor clinical outcome and higher mortality [53]. In our cohort, isolates originating from infected sites, but not colonization sites, exhibited high MICs to vancomycin raising a concern of clinical efficacy of the drug as monotherapy in this case. The method 
used to measure the MIC, E test, may have contributed to the increased MICs values [54]. However, a recent meta-analysis by van $\mathrm{Hal}$ et al. has shown that despite the methodology applied, these MICs close to the break point of 2.0, such as the isolates representing infected sites in this study, carry poor prognosis irrespective of the infection site [55]. Appropriate alternatives in such circumstances include daptomycin in cases of bacteremia and Linezolid in pneumonias.

Five new sequence types from seven samples are reported in this study (Table 6). All except one were isolated from infection sites. They belong to CC 80 according to the eBust website. Due to the diversity of nationalities working and living in the Gulf region, further studies should be conducted on MRSA to reveal and monitor the emergence of new strains.

\section{Conclusions}

A highly diverse population of MRSA isolates is reported from both carriers and patients' infection sites in our study from the Eastern Province in Saudi Arabia. Some of the isolate types were more prevalent among the carriers more than the infection sites. Therefore, screening and control measures should consider the polyclonal nature of the problem. A good understanding of the genetic spectrum of the MRSA isolates and its prevalence in the population calls for continuous surveillance and clearance measures. With SCCmec type IV being most prevalent; this suggests a community origin of most MRSA strains which is also supported by low resistance rates to clindamycin and sulfonamides. Therefore very well designed surveillance and intervention strategies, in particular restricting antimicrobial use, should be implemented to prevent emergence and control spread of MRSA in the community.

\begin{abstract}
Abbreviations
MRSA: methicillin resistant Staphylococcus aureus; S. aureus: Staphylococcus aureus; PBP2a: penicillin binding protein 2a; mecA gene: methicillin resistance gene; SCCmec: staphylococcal cassette chromosome mec; HA-MRSA: hospital acquired MRSA; CA-MRSA: community acquired MRSA; lukF-PV: leukocidin gene subunit F; lukS-PV: leukocidin gene subunit S; PVL: Panton-Valentine leukocidin; CC: clonal complexes; MLST: multi locus sequence typing; ST: sequence types; femA: factor essential for mecA; PCR: polymerase chain reaction; ICU: intensive care unit; MIC: minimum inhibitory concentration.
\end{abstract}

\section{Authors' contributions}

KRA: overall study design, raising fund, experimental design, and manuscript writing and editing. SR: experimental work and manuscript writing. FA: analysis of MLST sequences. AA: collection of bacterial isolates, collection of demographic data, and manuscript reading and editing. AD: collection of bacterial isolates. AKA: manuscript writing and editing. All authors read and approved the final manuscript.

\section{Author details}

1 Department of Epidemic Diseases Research, Institute for Research and Medical Consultations (IRMC), Imam Abdulrahman Bin Faisal University (IAU), P.O. Box 1982, Dammam 31441, Saudi Arabia. ${ }^{2}$ Department of Microbiology,
College of Medicine, Imam Abdulrahman Bin Faisal University (IAU), P.O. Box 1982, Dammam 31441, Saudi Arabia. ${ }^{3}$ Department of Biochemistry, College of Medicine, Imam Abdulrahman Bin Faisal University (IAU), P.O. Box 1982, Dammam 31441, Saudi Arabia.

\section{Acknowledgements}

The authors are grateful to Mr. Nestor Recella, Mrs. Janaika Yu Logan and the technical staff in the diagnostic microbiology laboratory (KFHU) for their technical assistance. The authors acknowledge the use of the S. aureus MLST database which is located at Imperial College London. This work is funded by the Deanship for Scientific Research at the University of Dammam (Project Number: 2013229).

\section{Competing interests}

The authors declare that they have no competing interests.

\section{Availability of data}

Please contact author for data requests.

\section{Consent for publication}

Not applicable.

\section{Ethics approval and consent to participate}

Ethical approval for the study was obtained from the Institutional Review Board at the University of Dammam (IRB-2013-08-023).

\section{Funding}

This work was funded by the Deanship for Scientific Research at the University of Dammam for Khaled R. Alkharsah (Project Number 2013229). The role of the funding body was financial support for the study and had no role in design of the study and collection, analysis, and interpretation of data and in writing the manuscript.

\section{Informed consent}

Not applicable.

\section{Publisher's Note}

Springer Nature remains neutral with regard to jurisdictional claims in published maps and institutional affiliations.

Received: 13 June 2017 Accepted: 8 March 2018

Published online: 15 March 2018

\section{References}

1. Conner-Kerr TA, Sullivan PK, Gaillard J, Franklin ME, Jones RM. The effects of ultraviolet radiation on antibiotic-resistant bacteria in vitro. Ostomy Wound Manag. 1998;44(10):50-6.

2. Chambers HF, Deleo FR. Waves of resistance: Staphylococcus aureus in the antibiotic era. Nat Rev Microbiol. 2009;7(9):629-41.

3. Wong H, Louie L, Lo RY, Simor AE. Characterization of Staphylococcus aureus isolates with a partial or complete absence of staphylococcal cassette chromosome elements. J Clin Microbiol. 2010;48(10):3525-31.

4. Liu J, Chen D, Peters BM, Li L, Li B, Xu Z, Shirliff ME. Staphylococcal chromosomal cassettes mec (SCCmec): a mobile genetic element in methicillin-resistant Staphylococcus aureus. Microb Pathog. 2016;101:56-67.

5. David MZ, Daum RS. Community-associated methicillin-resistant Staphylococcus aureus: epidemiology and clinical consequences of an emerging epidemic. Clin Microbiol Rev. 2010;23(3):616-87.

6. Seybold U, Kourbatova EV, Johnson JG, Halvosa SJ, Wang YF, King MD, Ray SM, Blumberg HM. Emergence of community-associated methicillinresistant Staphylococcus aureus USA300 genotype as a major cause of health care-associated blood stream infections. Clin Infect Dis. 2006;42(5):647-56.

7. Boyle-Vavra S, Daum RS. Community-acquired methicillin-resistant Staphylococcus aureus: the role of Panton-Valentine leukocidin. Lab Investig J Tech Methods Pathol. 2007;87(1):3-9. 
8. Deresinski S. Methicillin-resistant Staphylococcus aureus: an evolutionary, epidemiologic, and therapeutic odyssey. Clin Infect Dis. 2005;40(4):562-73.

9. Enright MC, Day NP, Davies CE, Peacock SJ, Spratt BG. Multilocus sequence typing for characterization of methicillin-resistant and methicillin-susceptible clones of Staphylococcus aureus. J Clin Microbiol. 2000;38(3):1008-15.

10. Otto M. MRSA virulence and spread. Cell Microbiol. 2012;14(10):1513-21.

11. Tokajian S. New epidemiology of Staphylococcus aureus infections in the Middle East. Clin Microbiol Infect. 2014;20(7):624-8.

12. Chen CJ, Wang SC, Chang HY, Huang YC. Longitudinal analysis of methicillin-resistant and methicillin-susceptible Staphylococcus aureus carriage in healthy adolescents. J Clin Microbiol. 2013;51(8):2508-14.

13. Dulon M, Peters $C$, Schablon A, Nienhaus A. MRSA carriage among healthcare workers in non-outbreak settings in Europe and the United States: a systematic review. BMC Infect Dis. 2014;14:363.

14. Dulon M, Haamann F, Peters C, Schablon A, Nienhaus A. MRSA prevalence in European healthcare settings: a review. BMC Infect Dis. 2011;11:138.

15. Monecke S, Coombs G, Shore AC, Coleman DC, Akpaka P, Borg M, Chow $H$, Ip M, Jatzwauk $L$, Jonas $D$, et al. A field guide to pandemic, epidemic and sporadic clones of methicillin-resistant Staphylococcus aureus. PLoS ONE. 2011;6(4):e17936.

16. CLSI. Performance standards for antimicrobial susceptibility testing; eighteenth informational supplement. In CLSI document M100-S26. Wayne: CLSI; 2016.

17. Al-Talib H, Yean CY, Al-Khateeb A, Hassan H, Singh KK, Al-Jashamy K, Ravichandran M. A pentaplex PCR assay for the rapid detection of methicillinresistant Staphylococcus aureus and Panton-Valentine Leucocidin. BMC Microbiol. 2009;9:113.

18. Mehrotra M, Wang G, Johnson WM. Multiplex PCR for detection of genes for Staphylococcus aureus enterotoxins, exfoliative toxins, toxic shock syndrome toxin 1, and methicillin resistance. J Clin Microbiol. 2000;38(3):1032-5.

19. Ghaznavi-Rad E, Nor Shamsudin M, Sekawi Z, van Belkum A, Neela V. A simplified multiplex PCR assay for fast and easy discrimination of globally distributed staphylococcal cassette chromosome mec types in meticillinresistant Staphylococcus aureus. J Med Microbiol. 2010;59(Pt 10):1135-9.

20. Rasmussen RV, Fowler VG Jr, Skov R, Bruun NE. Future challenges and treatment of Staphylococcus aureus bacteremia with emphasis on MRSA. Future Microbiol. 2011;6(1):43-56.

21. Monecke S, Skakni L, Hasan R, Ruppelt A, Ghazal SS, Hakawi A, Slickers $P$, Ehricht R. Characterisation of MRSA strains isolated from patients in a hospital in Riyadh, Kingdom of Saudi Arabia. BMC Microbiol. 2012;12:146.

22. Senok A, Ehricht R, Monecke S, Al-Saedan R, Somily A. Molecular characterization of methicillin-resistant Staphylococcus aureus in nosocomial infections in a tertiary-care facility: emergence of new clonal complexes in Saudi Arabia. New Microbes New Infect. 2016;14:13-8.

23. Moussa I, Shibl AM. Molecular characterization of methicillin-resistant Staphylococcus aureus recovered from outpatient clinics in Riyadh, Saudi Arabia. Saudi Med J. 2009;30(5):611-7.

24. Abou Shady HM, Bakr AE, Hashad ME, Alzohairy MA. Staphylococcus aureus nasal carriage among outpatients attending primary health care centers: a comparative study of two cities in Saudi Arabia and Egypt. Braz J Infect Dis. 2015;19(1):68-76.

25. Vandenesch F, Naimi T, Enright MC, Lina G, Nimmo GR, Heffernan H, Liassine N, Bes M, Greenland T, Reverdy ME, et al. Community-acquired methicillin-resistant Staphylococcus aureus carrying Panton-Valentine leukocidin genes: worldwide emergence. Emerg Infect Dis. 2003;9(8):978-84.

26. Bukharie HA. Increasing threat of community-acquired methicillin-resistant Staphylococcus aureus. Am J Med Sci. 2010;340(5):378-81.

27. Bae IG, Tonthat GT, Stryjewski ME, Rude TH, Reilly LF, Barriere SL, Genter FC, Corey GR, Fowler VG Jr. Presence of genes encoding the Panton-Valentine leukocidin exotoxin is not the primary determinant of outcome in patients with complicated skin and skin structure infections due to methicillin-resistant Staphylococcus aureus: results of a multinational trial. J Clin Microbiol. 2009:47(12):3952-7.

28. Otto M. A MRSA-terious enemy among us: end of the PVL controversy? Nat Med. 2011;17(2):169-70.

29. Li Z, Stevens DL, Hamilton SM, Parimon T, Ma Y, Kearns AM, Ellis RW, Bryant AE. Fatal S. aureus hemorrhagic pneumonia: genetic analysis of a unique clinical isolate producing both PVL and TSST-1. PLOS ONE. 2011;6(11):e27246.

30. Al-Bakri AG, Al-Hadithi H, Kasabri V, Othman G, Kriegeskorte A, Becker K. The epidemiology and molecular characterization of methicillin-resistant staphylococci sampled from a healthy Jordanian population. Epidemiol Infect. 2013;141(11):2384-91.

31. Harastani HH, Tokajian ST. Community-associated methicillin-resistant Staphylococcus aureus clonal complex 80 type IV (CC80-MRSA-IV) isolated from the Middle East: a heterogeneous expanding clonal lineage. PLoS ONE. 2014;9(7):e103715

32. Holmes A, Ganner M, McGuane S, Pitt TL, Cookson BD, Kearns AM. Staphylococcus aureus isolates carrying Panton-Valentine leucocidin genes in England and Wales: frequency, characterization, and association with clinical disease. J Clin Microbiol. 2005;43(5):2384-90.

33. Tokajian ST, Khalil PA, Jabbour D, Rizk M, Farah MJ, Hashwa FA, Araj GF. Molecular characterization of Staphylococcus aureus in Lebanon. Epidemiol Infect. 2010;138(5):707-12.

34. Enany S, Yaoita E, Yoshida Y, Enany M, Yamamoto T. Molecular characterization of Panton-Valentine leukocidin-positive community-acquired methicillin-resistant Staphylococcus aureus isolates in Egypt. Microbiol Res. 2010;165(2):152-62.

35. Udo EE, Sarkhoo E. The dissemination of ST80-SCCmec-IV communityassociated methicillin resistant Staphylococcus aureus clone in Kuwait hospitals. Ann Clin Microbiol Antimicrob. 2010;9:31.

36. Bekkhoucha SN, Cady A, Gautier P, Itim F, Donnio PY. A portrait of Staphylococcus aureus from the other side of the Mediterranean Sea: molecular characteristics of isolates from Western Algeria. Eur J Clin Microbiol Infect Dis. 2009;28(5):553-5.

37. Ben Nejma M, Mastouri M, Jrad BB, Nour M. Characterization of ST80 Panton-Valentine leukocidin-positive community-acquired methicillinresistant Staphylococcus aureus clone in Tunisia. Diagn Microbiol Infect Dis. 2013;77(1):20-4.

38. Djoudi F, Bonura C, Benallaoua S, Touati A, Touati D, Aleo A, Cala C, Fasciana T, Mammina C. Panton-Valentine leukocidin positive sequence type 80 methicillin-resistant Staphylococcus aureus carrying a staphylococcal cassette chromosome mec type IVc is dominant in neonates and children in an Algiers hospital. New Microbiol. 2013;36(1):49-55.

39. Tristan A, Bes M, Meugnier H, Lina G, Bozdogan B, Courvalin P, Reverdy ME, Enright MC, Vandenesch F, Etienne J. Global distribution of PantonValentine leukocidin - positive methicillin-resistant Staphylococcus aureus, 2006. Emerg Infect Dis. 2007;13(4):594-600.

40. Mariem BJ, Ito T, Zhang M, Jin J, Li S, Ilhem BB, Adnan H, Han X, Hiramatsu K. Molecular characterization of methicillin-resistant Panton-Valentine leukocidin positive staphylococcus aureus clones disseminating in Tunisian hospitals and in the community. BMC Microbiol. 2013;13:2.

41. D'Souza N, Rodrigues C, Mehta A. Molecular characterization of methicillin-resistant Staphylococcus aureus with emergence of epidemic clones of sequence type (ST) 22 and ST 772 in Mumbai, India. J Clin Microbiol. 2010;48(5):1806-11.

42. Huh K, Chung DR. Changing epidemiology of community-associated methicillin-resistant Staphylococcus aureus in the Asia-Pacific region. Expert Rev Anti Infect Ther. 2016;14(11):1007-22.

43. Boswihi SS, Udo EE, Al-Sweih N. Shifts in the clonal distribution of methicillin-resistant Staphylococcus aureus in Kuwait Hospitals: 1992-2010. PLoS ONE. 2016:11(9):e0162744.

44. Elhani D, Gharsa H, Kalai D, Lozano C, Gomez P, Boutheina J, Aouni M, Barguellil F, Torres C, Ben Slama K. Clonal lineages detected amongst tetracycline-resistant meticillin-resistant Staphylococcus aureus isolates of a Tunisian hospital, with detection of lineage ST398. J Med Microbiol. 2015;64(6):623-9.

45. Wang WY, Chiueh TS, Sun JR, Tsao SM, Lu JJ. Molecular typing and phenotype characterization of methicillin-resistant Staphylococcus aureus isolates from blood in Taiwan. PLoS ONE. 2012;7(1):e30394.

46. Mlynarczyk A, Szymanek-Majchrzak K, Grzybowska W, Durlik M, Deborska-Materkowska D, Paczek L, Chmura A, Swoboda-Kopec E, Tyski S, Mlynarczyk G. Molecular and phenotypic characteristics of methicillinresistant Staphylococcus aureus strains isolated from hospitalized patients in transplantation wards. Transplant Proc. 2014;46(8):2579-82.

47. El-Mahdy TS, El-Ahmady M, Goering RV. Molecular characterization of methicillin-resistant Staphylococcus aureus isolated over a 2-year period 
in a Qatari hospital from multinational patients. Clin Microbiol Infect. 2014:20(2):169-73.

48. Kechrid A, Perez-Vazquez M, Smaoui H, Hariga D, Rodriguez-Banos M, Vindel A, Baquero F, Canton R, Del Campo R. Molecular analysis of community-acquired methicillin-susceptible and resistant Staphylococcus aureus isolates recovered from bacteraemic and osteomyelitis infections in children from Tunisia. Clin Microbiol Infect. 2011;17(7):1020-6.

49. Scicluna EA, Shore AC, Thurmer A, Ehricht R, Slickers P, Borg MA, Coleman DC, Monecke S. Characterisation of MRSA from Malta and the description of a Maltese epidemic MRSA strain. Eur J Clin Microbiol Infect Dis. 2010;29(2):163-70.

50. Monecke S, Gavier-Widen D, Hotzel H, Peters M, Guenther S, Lazaris A, Loncaric I, Muller E, Reissig A, Ruppelt-Lorz A, et al. Diversity of Staphylococcus aureus isolates in European wildlife. PLOS ONE. 2016;11(12):e0168433.

51. Sarkar A, Raji A, Garaween G, Soge O, Rey-Ladino J, Al-Kattan W, Shibl A, Senok A. Antimicrobial resistance and virulence markers in methicillin sensitive Staphylococcus aureus isolates associated with nasal colonization. Microb Pathog. 2016;93:8-12.

52. Wang G, Hindler JF, Ward KW, Bruckner DA. Increased vancomycin MICs for Staphylococcus aureus clinical isolates from a university hospital during a 5-year period. J Clin Microbiol. 2006;44(11):3883-6.

53. Hidayat LK, Hsu DI, Quist R, Shriner KA, Wong-Beringer A. High-dose vancomycin therapy for methicillin-resistant Staphylococcus aureus infections: efficacy and toxicity. Arch Intern Med. 2006;166(19):2138-44.

54. Prakash V, Lewis JS 2nd, Jorgensen JH. Vancomycin MICs for methicillinresistant Staphylococcus aureus isolates differ based upon the susceptibility test method used. Antimicrob Agents Chemother. 2008;52(12):4528.

55. van Hal SJ, Lodise TP, Paterson DL. The clinical significance of vancomycin minimum inhibitory concentration in Staphylococcus aureus infections: a systematic review and meta-analysis. Clin Infect Diseases. 2012;54(6):755-71.

\section{Submit your next manuscript to BioMed Central and we will help you at every step:}

- We accept pre-submission inquiries

- Our selector tool helps you to find the most relevant journal

- We provide round the clock customer support

- Convenient online submission

- Thorough peer review

- Inclusion in PubMed and all major indexing services

- Maximum visibility for your research

Submit your manuscript at www.biomedcentral com/submit 